\title{
Talent dispositionalism
}

\author{
Catherine M. Robb ${ }^{1}$
}

Received: 23 August 2019 / Accepted: 27 January 2020 / Published online: 3 February 2020

(c) The Author(s) 2020

\begin{abstract}
Talents often play a significant role in our personal and social lives. For example, our talents may shape the choices we make and the goods that we value, making them central to the creation of a meaningful life. Differences in the level of talents also affect how social institutions are structured, and how social goods and resources are distributed. Despite their normative importance, it is surprising that talents have not yet received substantial philosophical analysis in their own right. As a result, the current literature is rife with conceptual ambiguity: a talent is referred to as all of a skill, potential, ability, capacity, endowment, and a natural gift. In response to this confusion, in this paper I develop an account of what a talent is, based on the debate concerning the metaphysics of ability and dispositions. I argue for a position that I call 'talent dispositionalism': $S$ has a talent for skill $A$ in circumstances $C$ iff $S$ has the general disposition to excellently develop and maintain $A$ when, in circumstances $C$, she tries to excellently develop and maintain $A$. On this account, a talent is not the skill itself, but a general iterated ability for the excellent development and up-keep of a particular skill, constituted by an agent's dispositional properties. I defend the account against four objections usually levelled against traditional dispositionalist theories of ability, and highlight some ways the account may influence debates in other areas of philosophical inquiry.
\end{abstract}

Keywords Talent $\cdot$ Ability $\cdot$ Disposition $\cdot$ Potential $\cdot$ Excellence $\cdot$

New dispositionalism

\section{Introduction}

Identifying and developing our talents often plays a significant role in our lives. We will most likely take our talents into consideration when deciding what subjects to study at school, which career path to take, or what hobbies to pursue. Cultivating our talents

Catherine M. Robb

c.m.robb@uvt.nl

1 Department of Philosophy, Tilburg University, Tilburg, The Netherlands 
might also define who we are and what we value, making them central to our identity and the creation of a meaningful life. Talents do not only influence prudential choices, but the resources produced and consumed by nurturing our talents can also affect how social goods are distributed, and how social institutions are structured. Given the importance of talents to our personal and social lives, it is surprising that talents have not yet received substantial philosophical discussion as an object of analysis in their own right.

As an exception, the implications of identifying and developing talents are discussed in the literature dealing with moral and political obligations. For instance, Kant, and contemporary moral perfectionists such as Thomas Hurka, claim that we have a moral obligation to develop our talents, ${ }^{1}$ whilst in the literature on distributive justice, talents are discussed as a disruptor of social equality and fairness. ${ }^{2}$ Talents are also mentioned briefly in the debate on how to determine the value of our achievements. For example, Bradford (2013) argues that the value of our achievements should not take into account the talent-level of the agent but rather the difficulty of the achievement, whilst von Kriegstein $(2017 ; 2019)$ and Hirji (2019) argue that talents can (and perhaps should) amplify or increase the value of an achievement. ${ }^{3}$ Throughout these discussions, however, there is no systematic explanation of what a talent is, or what it means for someone to be talented. As a result, the literature is rife with conceptual ambiguity: a talent is simultaneously referred to as an 'ability', an 'inherent capacity', a 'natural gift', 'native endowment', and a particular type of 'skill'.

This conceptual ambiguity is also prevalent in everyday language. For example, in most sports commentaries we often hear athletes being called 'talented', but it's not very clear what this means. It might be that a young athlete is called 'talented' when referring to their promise or potential. Here, the athlete's potential acts as a counterfactual predictor for the level of exceptional skill that she may go on to achieve if this potential is further developed. By contrast, when we hear that a well-seasoned athlete is talented, this cannot mean that she merely has the potential to develop an excellent skill, as she is already highly skilled and already displays an exceptional ability. Thus, there seems to be two substantial yet competing notions of what a talent is. On the one hand, a talent is considered to be an ability or skill that the talented person can already perform or express excellently. On the other hand, a talent is also referred to counterfactually, as a type of potential yet to be expressed or developed into an excellent performance. These two definitions of talent can come apart and are at least prima facie incompatible: (1) talent as a potential for skill excellence, and (2) talent as the excellent expression of a particular skill.

In what follows, I argue for a dispositionalist account of talent that reconciles both of these seemingly inconsistent intuitive definitions. A talent, I suggest, is not to be understood as the excellent demonstration or expression of a skill, nor as the skill itself, but rather as an excellent ability for the development and maintenance of a particular skill. Being talented is a description of the way in which we develop a skill, rather than

\footnotetext{
${ }^{1}$ See for example Kant (2010, pp. 32-33) and Hurka (1993, pp. 15, 96).

2 See for example Cohen (2011, pp. 19, 30), Dworkin (2000, pp. 92, 97), Rawls (1999, pp. 63, 73), Fishkin (2014), Shields (2016) and Sher (2012).

3 Thanks to an anonymous reviewer for highlighting the relevance of talent to this debate.
} 
a description of the skill itself. This descriptive ability is 'modal', such that it only manifests in certain conditions, and it is 'higher-order' (or what is sometimes called 'iterated'), such that it is an ability to acquire another ability-the ability to be able to $\Phi$. I call this position 'talent dispositionalism', as it specifically highlights three necessary characteristics of a talent: (1) that it is modal, (2) that it is a dispositional feature of an agent, and (3) that this disposition constitutes the general, iterated ability for the excellent development and up-keep of a particular skill. In particular, I defend a version of talent dispositionalism inspired by 'new dispositionalism' and its emphasis on agential intention: $S$ has a talent for skill $A$ in circumstances $C$ iff $S$ has the general disposition to excellently develop and maintain $A$ when, in circumstances $C$, she tries to excellently develop and maintain $A$.

The paper will be structured as follows. In the next section I outline the desiderata for an account of talent, and argue that we ought to consider talent as a particular type of disposition for a skill, rather than being a skill itself. This means that the account of talent I propose rests on a dispositional account of ability. In Section Three I argue that despite good initial odds, talent dispositionalism ought not to be specifically defined as a version of 'success dispositionalism', and in Section Four I argue instead for a version of 'new dispositionalism', constituting talents as a general, higher-order disposition for a skill that is indexed to agential intention. I defend the new dispositionalist account of talent against three objections, and in doing so flesh out the account in more detail. In the final section I conclude and gesture at some ways in which providing a systematic dispositionalist account of talent may impact upon debates in other areas of philosophical inquiry.

\section{Talents and dispositions}

If someone is talented, at the very least it is necessary that they have the potential to perform the action in which they are considered to be talented. The talented singer, for example, has the potential to sing: she has vocal chords, she can vibrate these vocal chords and control their vibrations in response to other sounds. These categorical features of the singer-her physical constitution and musical intuitiveness- together result in her potential to sing. It seems uncontroversial to state, then, that a talented agent will have categorical features that are the bases of her potential to perform the skill in which she is deemed to be talented.

It has been widely assumed that these categorical features are 'natural', 'native' or 'innate' to the agent. This assumption has been challenged most notably in the fields of psychology and epigenetics, where experiments have shown that there can be no such thing as solely natural potential that is unmediated by one's social environment (see for example Howe et al. 1998; Fishkin 2014). This means that one's potential can have as its bases a number of physiological and physical mechanisms that have been caused by an iterative interaction between both genetic and environmental factors. ${ }^{4}$ For the purposes of the account of talent that I argue for here, nothing rests on whether

\footnotetext{
4 For epigenetic accounts that emphasise the iteration between both genetic and environmental factors, see Beck et al. (1999), Eckhardt et al. (2004), Weinhold (2006), Howe et al. (1995), and Sloboda et al. (1996).
} 
an agent's potential for a particular skill is a result of either genetic or environmental factors, or as an interaction between the two. For now it is enough to claim there is such a potential, and that this arises as result of certain categorical features of an agent.

The potential that constitutes an agent's talent has to be more than just mere features of an agent that would enable her to perform any kind of skill at any level. The nontalented singer also has the potential to sing; she can also vibrate her vocal chords and control the vibrations in response to other sounds, and this may allow her to take part in other kinds of activities, like talking or whistling. The difference between the talented and non-talented singer must rest on either the kind or degree of potential that they possess. The potential that constitutes a talent is one that allows the agent to reliably express, develop and maintain a particular skill to an excellent standard. As such, the talented singer's potential has to meet two conditions that the non-talented singer's potential does not: talent-potential is (1) reliable-the reliability condition, and (2) realised in an excellent development of the skill in question-the excellence condition. $^{5}$

There are two further necessary conditions that must be met in order to plausibly characterise potential qua talent. First, the talent-potential must be indexed to a particular agent, so it is a feature specifically of the agent to whom the talent belongs. As such, talent-potential is agent specific and relates to only agentive abilities. Second, whilst it may be possible for an agent to have many exceptional categorical features that give rise to the potential to realise a number of skills, a talent is indexed to a particular skill. For example, if an agent has vocal chords and can control the vibrations emitted from them, she may be able to sing, recite poetry, shout loudly, and give rousing political speeches. But if the agent is talented, we have to be able to ascribe the skill that is indexed to that talent; she may be a talented singer but not a talented speech-giver, even though she has the potential to express both skills. As such, talent-potential is domain specific, even if the features of the agent that give rise to this potential also give rise to potential for other skill domains.

There are now four desiderata that an account of talent-potential must meet: (1) agent specificity, (2) domain specificity, (3) reliability, and (4) excellence. In order to meet these four conditions successfully, I propose that the kind of potential that constitutes a talent must be understood as dispositional, characterised by what an agent is reliably 'bound' or 'liable' to do when exposed to certain stimuli conditions (see Ryle 1949, p. 31). As a particular type of potentiality, a disposition is indexed to a specific object or agent, and describes what that object or agent can do under a set of appropriate circumstances. A glass, for example, is disposed to break in the event of being struck, and a piece of wood is disposed to be turned into furniture in the event of being carved. Analogously, a talented agent is disposed to excellently manifest a particular skill in the event of developing that skill. In the case of talent, an agent's

\footnotetext{
5 Determining what counts as particularly excellent skill development will depend on the skill domain itself, as well as relevant social and cultural values. See for example Seel (2012,p. 3262), who claims that the threshold for what counts as exceptional ability is kept relatively high, so that a talent designates a rare group. See also Winner (2000, p. 153) and Csikszentmihalyi (1998, p. 411) for a discussion of the normative and cultural values that might constitute these thresholds. However, for the purposes of my argument I do not need to specify exactly what threshold of excellence we ought to adopt, only that what counts as a talent is, in part, contextually-sensitive and comparative to whatever standard of excellence is adopted.
} 
disposition will denote the potential for the excellent development and maintenance of a particular skill. ${ }^{6}$ Considering talent-potential as a disposition makes room for the fact that a talent is agent specific, domain specific, and to be characterised as the excellent expression of one's skill. This meets conditions (1), (2), and (4) as discussed above.

Dispositions are also a natural fit for accommodating condition three, which specifies the reliability of the talented agent's potential. Dispositions come with an in-built reliability condition; they attribute that an agent is likely to manifest her potential under a set of circumstances, that she is liable or bound to do so, and that we can expect the actualisation of her potential with reasonable certainty. This reliability condition has been spelled out in a number of ways. ${ }^{7}$ It is not necessary to settle here on a specific formulation of the condition, but only to note that for an account of talent it must meet two requirements: it can neither be too strong, nor too weak. The former requirement is important because the reliability condition should not ascribe to the talented agent the disposition to develop her skill in all and every possible circumstances. Presumably, there are times when, for example, the talented violinist will pick up her violin with the intention of playing around with sounds and musical gestures, rather than exhibiting musical excellence or exceptional technique. The talented sprinter might decide to go for a slow jog, rather than run to the best of her ability. It might also be the case that external factors sometimes impede the talented agent's excellent expression of her skill, but this does not mean that she would not reliably manifest this excellence when these impediments are removed. ${ }^{8}$

The second requirement is important, because the reliability condition should not be so weak that it renders the talented agent as hardly ever expressing her potential. Reliability is one of the factors that differentiates the talented from the non-talented agent, and so we have to maintain that talent-potential attributes stronger tendency for successful and excellent skill expression. For example, whilst I may have the potential to play football in virtue of the fact that I have two legs and good co-ordination, it would be inaccurate to claim that I have the disposition to do so. It is not the case that I can reliably express a skill for football under appropriate circumstances, and it is certainly not the case that I am likely to do so excellently. Merely having the potential for a particular skill does not necessarily result in having the disposition to express

\footnotetext{
6 The relation between 'development' and 'maintenance' is phrased as a conjunction rather than a disjunction, because the account needs to rule out instances in which someone might excellently develop a skill when they first begin, but fail to continue this level of development. Maintenance should be understood as a form of continual up-keep and development, and is often a reason why we ascribe talent-think of an athlete who continually improves and develops her skill. Thanks to an anonymous reviewer for highlighting this clarification.

7 For example, Manley and Wasserman (2008) state that an agent has a disposition to $\Phi$ if she $\Phi s$ across a wide range or proportion of suitable circumstances, Peacocke (1999) understands reliability in terms of there being a 'close possibility' that the manifestation of the disposition will obtain under a set of appropriate circumstances, and Maier (2015) states that reliability should be understood as $\Phi$-ing in a sufficient proportion of possible worlds.

8 See for example the well-known objections posed against strong reliability conditions, such as the masking objection (Johnston 1992) and the finking objection (Martin 1994). These objections arise due to dispositions having a modal, conditional structure. However, just because these objections have been raised, it does not mean that any reliability condition is not plausible. In Section Three, I indicate how the new dispositionalist emphasis on intention seems to offer a plausible response to these objections, specifically for talents.
} 
that skill. ${ }^{9}$ The talented, as opposed to the non-talented agent, will display the dispositional features that result in her having a higher tendency of excellently expressing a particular skill under the right circumstances, and this is why the reliability condition is so important. The conditions under which a talented agent reliably manifests her disposition $D$ must be broad enough to allow for the fact that she has a higher tendency than the non-talent agent to excellently manifest $D$, and narrow enough to exclude lack of intention and external impediments.

When attributing the 'appropriate' conditions for reliability of excellent skill development, we similarly need to ensure that they do not include comparatively more effort, practice or support in the process of skill development. This is because one marker of the excellence that comes with a talent is the agent's seemingly 'natural' ability to develop a skill without the amount of effort, practice and support that a non-talented agent would need. The talented pianist is able to reach the same standard as a non-talented pianist, but with less effort and support. This is why the excellence condition is so important: it limits the range of conditions that count as being relevant or appropriate for the reliable and successful manifestation of the disposition. These restrictions can be described in general terms, such as the comparatively reduced amount of practice time or support needed to reach the same level as a non-talented agent, but the specificities of what this actually entails will be domain-specific and context-dependent. ${ }^{10}$

It could be objected that it is not plausible to characterise excellent skill development in terms of comparatively low levels of effort, practice or support. Instead, we might consider skill development as excellent if it is done so deliberately or conscientiously. I do not deny that there are many ways to excellently develop a skill, and doing so with deliberate action and thoughtfulness may be two of these. But deliberate and thoughtful action can be shared by both the talented and non-talented agent; both Serena Williams and I might practice with dedication and thoughtfulness, but it is still the case that Serena is a more talented tennis player than I am. Whilst a talent might involve a variety of developmental excellences, an account of talent should determine what differentiates a talent from other kinds of ability. So, even if both Serena and I develop our skills with deliberate and thoughtful action, it is Serena that will do so with comparatively less effort, practice or support, and it is this that characterises her talent. $^{11}$

This also helps to explain why a talent cannot be characterised as the excellent level of skill itself, but rather the excellent way in which a skill is developed and maintained.

\footnotetext{
9 For a similar statement regarding the relationship between potentiality, dispositions and reliability, see Vetter's claim that potentials and dispositions are on a "spectrum" of potentiality (2015,p. 101). For example, with regards to fragility, "the potentiality to break, is possessed by all the objects on our spectrum, though to different degrees". What differentiates the points on this spectrum is, to a certain extent, context-specific (ibid., p. 21).

10 These restrictions leave room for the fact that many high-level performance domains, such as theoretical physics or brain surgery, require decades of dedicated practice and instruction, and can still be something for which we have a talent. The talented brain surgeon will be the one who requires comparatively less practice-time and effort than someone who is not talented in that domain. In these cases, it is highly likely that those who perform these high-level skills have already out-performed their peers even before specialised training begins. Thanks to an anonymous reviewer for raising this point as an initial objection.

11 Thanks to an anonymous reviewer for raising this objection.
} 
It might be the case that a non-talented agent and a talented agent, at some point, will reach the same high level of skill. If a talent were merely the indication of a high level of skill, it would be impossible to pick out those who are deemed to be talented from those who are not. What does distinguish the two agents with the same level of skill is the way in which they develop their skill; those who are talented will develop their skill with comparatively less effort, practice and support to reach the same level as those who are not.

Understanding talents in this way also makes sense of how talented children who do not yet display an excellent expression of a skill can still be considered as talented. We can, on my view, claim that someone is talented even though they do not yet have an excellent skill. The talent is the counterfactual ability for excellent skill acquisition and maintenance, rather than the ability for the skill expression itself. This means that a talent is not just a disposition but a higher-order or iterated disposition; a disposition "for the having of further dispositions" (Borghini and Williams 2008, p. 30). ${ }^{12}$ For example, the five-year old pianist may be considered as an 'average' pianist by musical standards, yet still be classed as talented depending on the way in which she develops and maintains her skill. The 'talent' of the agent is the disposition to be disposed to play the piano in a particular way (excellently); it is not the disposition to excellently express the skill itself, but the disposition to be able to excellently acquire and maintain the skill, at whatever level that skill may be, and in whatever way we decide to conceptualise what skills are. ${ }^{13}$

To summarise, talents are constituted by the potential for excellent development and maintenance of a particular skill. This potential is best understood as a higherorder disposition, which is a feature of a particular agent and indexes that agent to a particular skill domain. Whilst it is possible for a non-talented agent to also possess the potential for the expression of a particular skill, the potential of the talented agent is necessarily dispositional, ascribing a tendency or reliability for the manifestation of that potential under an appropriate set of conditions. These conditions are specified and limited by the excellence condition, referring to the excellent way in which a skill is acquired, developed and maintained, rather than the excellent expression of the skill itself.

If talents are constituted by the higher-order dispositional features of an agent, then the account of talent I am proposing here is grounded in a dispositionalist account of ability, which holds that abilities are constituted by agential dispositions. There are two main types of dispositionalist theories that have gained traction in the literature on ability: 'success dispositionalism' and 'new dispositionalism'. Both of these accounts have been subject to various objections, the most detrimental of which claim that it is undesirable and implausible to formulate an ability in terms of a disposition (see specifically Vetter 2019; Vetter and Jaster 2017). If these objections hold, then a dispositionalist account of talent would also be implausible. However, I consider talent dispositionalism to be able to successfully respond to these objections. In the next section I introduce the theory of 'success dispositionalism', and defend it against

\footnotetext{
12 See also Vetter (2015, p. 36), who describes higher-order abilities as iterated.

13 See Stanley and Williamson's recent (2017) paper defending the claim that skills are by nature dispositional. However we define the nature of skills, this does not impact on the plausibility of 'talent dispositionalism' as argued for in this paper.
} 
the 'triviality' objection. However, I will also show that success dispositionalism is not comprehensive enough for an account of talent, and instead we ought to consider talent dispositionalism as a version of 'new dispositionalism', which emphasises the importance of agential intention rather than merely 'exercise-success' of a particular skill.

\section{Talents and success}

The success account of dispositional ability holds that the disposition that constitutes an ability is one that an agent successfully manifests, or performs well, whenever they manifest the disposition: ' $A$ has the ability to $\Phi$ iff $A$ is disposed to $\Phi$ successfully, when $\Phi$ ing at all' ${ }^{14}$ This formulation of ability is naturally tailored to an account of talent, because tying an agent's talent to the evaluative condition of success looks like a version of the excellence condition that was one of the initial desiderata. As such, the success account of dispositional talents would be formulated something like this: ' $A$ has a talent for skill $\Phi$ iff $A$ is disposed to develop or maintain $\Phi$ excellently, when developing or maintaining $\Phi$ at all'. For example, a violinist would be talented if she can excellently (successfully) develop her skill for playing the violin whenever she does so, and a footballer is talented just in virtue of the fact that whenever she does develop her skill for football, she does so excellently (successfully).

Success dispositionalism is objected to on account of its supposed triviality (Vetter and Jaster 2017, p. 8; Vetter 2019, pp. 214-216). The worry is that there are some abilities such that as soon as they are performed, their performance renders them a success. Take for example the ability to lift my leg; if I am disposed to lift my leg successfully when I lift my leg at all, then as soon as I do so I have already met the success condition. Merely performing the action is enough to mean that I have an ability for doing so, which results in the success account being trivial and uninformative. It simply states that an agent is able to successfully perform an action when they are able to successfully perform an action, rather than giving an account of what it means to successfully perform that action.

The triviality objection may be problematic for particular kinds of abilities, however I argue that it does not pose a worry for a dispositionalist account specifically indexed to talent. This is because the success condition that constitutes a talent is not merely a requirement for the successful performance of a skill, but rather the excellent performance of that skill. The success condition of the dispositional account of talent is the excellence condition, and renders the success condition substantial enough not to be considered as trivial. For example, William may have the ability to play the piano insofar as he is playing the piano successfully, but this does not mean that he has a talent to play the piano. This would require him to have the higher-order disposition to excellently develop the skill to be able to play the piano. The triviality objection against success dispositionalism therefore fails as an objection against talent dispositionalism, due to the necessary inclusion of the excellence condition.

\footnotetext{
14 See for example similar formulations of this success account in Vetter and Jaster (2017, p. 7), Greco (2010), Sosa (2015) and Carter (2019).
} 
Although a success dispositionalist account of talent would be able to meet the triviality objection, the account is not comprehensive; it does not pay due attention to the role of intention that comes with abilities. I may, for example, be able to excellently develop a skill for playing chess, but hate to do so because I feel pressured by my parents. When I'm forced to practice and develop my chess skills I might intentionally refrain from excellently doing so, playing as poorly as I can, and making sure I do not learn the relevant moves or strategies. Even though I have the talent for playing chess, it is not the case that I excellently develop that skill whenever I do so- there are times when I will intentionally do the opposite.

In order to respond to this worry, I argue that talent dispositionalism should be a specific version of 'new dispositionalism', which advocates that the manifestation conditions of a dispositional ability are only appropriately realised when an agent is in a set of relevant circumstances, and importantly, when that agent intends to act in those circumstances. ${ }^{15}$ In the next section I will outline this account of dispositional ability, and defend its extension to talents against three potential objections.

\section{Talent and new dispositionalism}

New dispositionalism is an account of ability that indexes the successful manifestation of an ability to the agent's intention under a set of relevant circumstances: ' $S$ has the ability to $A$ in circumstances $C$ iff she has the disposition to $A$ when, in circumstances $C$, she tries to $A^{\prime}$ (see Fara 2008, p. 248). ${ }^{16}$ When this formulation of ability is extended to an account of talents, the inclusion of the excellence condition means that success dispositionalism does not have to be rejected altogether. There is still a success condition, fleshed out as the excellence condition, and expanded upon with new dispositionalism's emphasis on intention and context. As such, a new dispositionalist account of talent would read: ' $S$ has a talent for skill $A$ in circumstances $C$ iff $S$ has the disposition to excellently develop and maintain $A$ when, in circumstances $C$, she tries to excellently develop and maintain $A$ '.

There are three potential objections that have been raised against the new dispositionalist account of ability: (1) the reliability objection, (2) the trying objection, and (3) the averted attempts objection (see Vetter 2019; Vetter and Jaster 2017). My contention is that when these objections are applied more specifically to a dispositionalist account of talent, they do not hold. I will respond to each objection in turn, emphasising in particular the specific desiderata that come with an account of ability qua

\footnotetext{
15 Carter (2019) has recently argued against the success account of ability-exercise, that in fact it is possible to exercise an ability $\Phi$ without successfully $\Phi$-ing, but instead doing something entirely different. Extended to a success account of talent dispositionalism, the question would be whether it might be possible for an agent have a talent for skill $\Phi$ but manifest that talent by (also) demonstrating skill $\psi$. There are two responses to this objection. First, because a talent is indexed to a particular skill, it could be that talent dispositionalism is able to circumvent the objection altogether. A talent would be a kind of ability that just has to be indexed to one skill domain or type of activity. Second, we could just accept the objection and agree that a talent for a particular skill can manifest and be exercised in a number of ways.

16 See also, for example, Clarke (2009) and Vihvelin (2004) for a similar formulation of new dispositionalism.
} 
talent - that the nature of talents is necessarily constrained by both the reliability and the excellence conditions, and that talents are general, higher-order dispositions.

\subsection{The reliability objection}

New dispositionalism claims that abilities are dispositional. However, this has been argued against by providing examples in which an ability and its supposed disposition come apart. Consider the example of spontaneous creative abilities, such as writing a poem or compositing a piece of music; these abilities may arrive as once-in-a-lifetime flashes of inspiration, or a spur of the moment creation (Vetter 2019, pp. 208-209; Vetter and Jaster 2017, pp. 6-7). As such, there is no relevant disposition, and there is no intention; the agent is not liable or likely to compose poetry or a piece of music even if they tried. In these circumstances we would say of the agent that they have been able to write a poem, or compose a piece of music, even though they are not disposed to do so. The objection rests on the assumption that abilities can be constituted by only one instance of a successful performance, and so are not necessarily dispositional.

This reliability objection does not worry an account of talent dispositionalism. I have characterised talents as dispositional features of an agent, precisely because of the strong reliability condition that comes with disposition ascriptions. When an ability is understood specifically as a talent, it will always be subject to this reliability condition, and so the talent and disposition cannot come apart in the way that the example above suggests. A dispositional account that does not allow for spontaneous achievements to count as a talent is exactly what we are looking for. In this case, talent dispositionalists will happily bite the bullet and accept that once-in-a-lifetime abilities do not count as a talent.

We might want to say of the person who only writes one inspirational poem in their lifetime that they have been able to do so, but it would be strange to claim that they have a talent to do so. Such a concession is not controversial, and also tracks the way in which we understand abilities more generally. In the literature, there is a subtle bipartite distinction made between 'having an ability' to perform an action and merely 'being able' to do so. It is only the latter that allows for spontaneous abilities without any reliability condition. When claiming, for instance, that a poet has an ability to write poetry, rather than merely being able to do so on one occasion, fluke-success should not be a sufficient condition for having that ability.

In the literature, the having of an ability is usually termed a 'general' ability, and being able to perform an action once under certain circumstances is usually called a 'particular' or 'specific' ability. ${ }^{17}$ A general ability is one that an agent possesses even if she is not in the appropriate circumstances that would allow her the opportunity or option to perform the ability in question. Nonetheless, if an agent has a general ability, we expect that she would reliably perform under the right circumstances. For example, I may have a general ability to play tennis but I am not able to do so now

\footnotetext{
17 Honoré makes the distinction between particular and general abilities (1964), whilst Maier makes the distinction between specific and general abilities (2010; 2015). Whittle uses a completely different vocabulary and makes the distinction between local and global abilities (2010). There are subtle differences to each of these accounts.
} 
because there are no more tennis balls on the court. The lack of tennis balls removes the opportunity for me to express my general ability. Honoré (1964, p. 465) terms this general ability as a 'competence', as it comes with a reliability condition; it ascribes the agent with a tendency to actualise her disposition when doing so is made available to her by the relevant circumstances. Maier (2015) makes this clear when he describes the ascription of general abilities as 'robust', depending on what an agent can do under a wide range of circumstances rather than merely what she can do at a particular time. This is exactly the kind of reliability that comes with a talent.

A specific ability, on the other hand, ascribes only to an agent what they can do under a particular set of circumstances, and at a particular time. ${ }^{18}$ For example, I may have a general ability to play tennis, but if there are no more tennis balls then my inability to play tennis in that moment counts as a lack of a specific ability. An agent has a specific ability, when as Maier claims, there is "nothing between her and the deed" (2015, p. 123).

With this distinction in mind, it can be qualified that talents are 'general' abilities, indicating a competence that involves a robust reliability condition. The spontaneous, once-in-a-lifetime abilities highlighted by the objection are only 'specific' abilities which do not require any kind of reliability. It would seem that the objection can be responded to just by reinforcing this already held distinction between the two types of abilities.

However, the difference between general and specific abilities does not fully solve the worry posed by the reliability objection. This is because in the literature it is not clear how specific abilities and general abilities stand in relation to one another. On one reading, it seems as if to have a specific ability an agent must already have a general ability, combined with a further condition of appropriate circumstances or an 'opportunity' or an 'option' (see Maier 2010; 2015, p. 123). This cannot be my view, as in order to respond to the objection I need to be able to claim that spontaneous abilities are present in the absence of general abilities. Furthermore, Whittle describes her version of specific abilities ('local' abilities) as having a reliability condition, albeit a very weak one. She claims that even 'local' ability ascriptions do not allow for spontaneous action on one occasion, but that there must be "a reliable connection between being in a particular set of circumstances" and having the same "outcome" (Whittle 2010, pp. 3-4). Here it seems as if the difference between a specific and general ability is understood in terms of the degree of robustness of the reliability condition. This also cannot be my view, as in order to respond to the objection, I need to be able to claim that spontaneous abilities do not involve any reliability.

The kind of once-in-a-lifetime abilities that are used as examples by the objection cannot be 'specific' abilities, understood in the way characterised above. Instead, I suggest that they are what Mele calls 'simple' abilities, merely ascribing to an agent what they can do at a specified time and under specific circumstances: "an agent's $A$-ing at a time is sufficient for his having the simple ability to $A$ " (Mele 2003, p. 448). For example, if Serena hits a tennis ball on the baseline, she is 'simply' able to do it whether or not she was trying to do so, avoiding to do so, and irrespective of whether

\footnotetext{
$\overline{18}$ Mele also makes this distinction between specific and general practical abilities (2003, specifically p. 447).
} 
she has previously done so, or could do so again. Someone with a general ability to $A$ might, under the right circumstances, demonstrate the simple ability of $A$-ing, but it is not necessarily the case that the demonstration of $A$-ing implies the general ability to $A$. The fact that an agent has a simple ability to $A$ does not necessarily require the general ability.

In this case, instances of fluky-success are examples of Mele's 'simple' abilities - they do not require a reliability condition nor do they require agential intention. But talents are not simple abilities, nor are they specific abilities. A talent is a general dispositional ability to excellently develop and maintain a particular skill; an agent is talented insofar as she has a reliable tendency to actualise her disposition, when doing so is made available to her by the relevant circumstances and when she intentionally tries to do so. Because talents are general abilities, they cannot be separated from the reliability condition in the way that simple abilities can, and the condition is more robust than for specific abilities. This means that the new dispositionalist account of talent can respond to the reliability objection, and is to be revised as follows: ' $S$ has a talent for skill $A$ in circumstances $C$ iff $S$ has the general disposition to excellently develop and maintain $A$ when, in circumstances $C$, she tries to excellently develop and maintain $A^{\prime}$.

\subsection{The trying objection}

An ability might also come apart from a disposition due to the agent's intention to manifest the disposition. It has been objected against new dispositionalism that some abilities can only be actualised when the agent specifically does not try or intend to bring about the actualisation (Vetter 2019, pp. 207-208; Vetter and Jaster 2017, p. 6). There are three examples given: the first two are cases of the ability to absentmindedly play with one's jewellery or the ability to be spontaneous, where in both cases intending or trying to do so would be self-defeating. The third example is of complex actions, such as playing a difficult piece on a musical instrument, or mountain biking, both of which are constituted by a variety of movements (such as moving one leg in a certain direction, or one finger at a specific speed). The ability to perform these complex actions is only possible, so it is argued, because we do not try to perform each and every specific movement. We can only perform each movement as part of the entire complex action. In this case, even though I do not intend to move my leg in a clockwise direction, I still have the ability to do so. In fact, the ability here depends on my not intending it, and instead intending some other more complex movement.

However, similarly to the reliability objection, the trying objection against new dispositionalism is not a worry for an account of talent dispositionalism. This is because of two desiderata that an account of talents must meet-talents ascribe the reliable and excellent development and maintenance of a particular skill. Usually this skill is a complex action, like playing the piano or riding a mountain bike, and those who raise the trying objection admit that these complex actions are ones we usually intend. But even if we can say that someone is talented at a non-complex skill, like moving one's leg in a clockwise direction or one's finger to a syncopated rhythm, we could only do so because they reliably and excellently develop and maintain that skill. Developing 
a skill involves repeated performance and practice, and if it is not possible for an agent to repeat a performance of the skill intentionally, then they are not reliably or excellently developing that particular skill. By unintentionally moving my left hand in a syncopated rhythm I might be contributing to the talent I have for playing piano, but this does not imply that I have a talent for moving my left hand in that way.

The point here is not that reliability necessarily implies intention or trying, as this would potentially beg the question, but rather that instances of having an ability that are only possible when not trying, are not eligible to count as talents, and so they do not worry an account of talent dispositionalism. This is also the case for the first two types of examples that come out of the objection, absent-minded and spontaneous abilities where trying would be self-defeating. I have already addressed the worry of spontaneous abilities in the previous section, arguing that these count as 'simple' abilities. The same point can be made with regards to absent-mindedly playing with one's jewellery. Whilst it may be true that I am able to do so (either in terms of a simple or specific ability), it is another question altogether whether I have a general ability to do so. My suspicion is that in most cases of absent-minded displays of ability, the agent does in fact have a general ability too; the 'absent-mindedness' does not describe the ability itself, but rather it is an adverb which describes the way in which the ability is expressed and manifested (in the same way I might describe the way I run, slowly or quickly). So, if for sake of argument it is possible to be talented at playing with one's jewellery, you may be talented at doing so and also be able to express that talent absent-mindedly. This is not incompatible, as the talent describes the way in which the skill is developed and maintained, whereas the adverb (here, 'absent-mindedness') describes the way in which a particular skill is expressed in a particular moment.

Given these responses, talent dispositionalism can be defended against the trying objection, in virtue of the fact that an account of talent must meet both the reliability and excellence conditions, and that talents are general abilities rather than specific or simple ones.

\subsection{The averted attempts objection}

The previous two objections against new dispositionalism aimed to show that abilities and dispositions come apart, by giving examples of when it is possible to have an ability without the relevant disposition. The averted attempts objection, however, aims to demonstrate that it is possible to have the relevant disposition, but not the corresponding ability. Vetter and Jaster (2017, pp. 3-4) give the example of Betty, who is in a coma, and so it seems intuitive to claim that she is unable to raise her arm-the coma prevents her from doing so. The new dispositionalist, by contrast, would have to say that Betty $i s$ able to raise her arm, because according to their account of ability, Betty has the disposition to raise her arm if she would try to do so. The new dispositionalist cannot, so it is argued, accommodate the fact that Betty's coma prevents her from trying to raise her arm in the first place, and so prevents her from having the relevant ability.

According to Vetter and Jaster, the reason for this disanalogy between abilities and dispositions is due to the fact that dispositions are modal-they ascribe features to an agent even when the stimulus that leads to the manifestation of the disposition are 
'systematically blocked'. Abilities, however, should not be construed as modal-they are meant to ascribe features to an agent that she is actually in a position to 'initiate' and express given the current circumstances. Betty's coma prevents her from initiating any internal mechanisms that would enable her to raise her arm, and as such, we should state that whilst she may have the disposition to do so, Betty does not have the ability.

There are two ways to respond to this objection. First, we can simply add a possibility condition to the formulation of new dispositionalism, such that an agent has an ability $A$ only when in circumstances that would mean it is possible for the agent to try to $A$. Although this formulation renders an agent's ability to be in part determined by external circumstances, it would mean that Betty is no longer considered as having the ability to raise her arm. This is because she would not be in the relevant circumstances that make doing so possible-her coma prevents that possibility. Such a possibility condition could easily be accommodated by new dispositionalism in their clause that states a disposition should be manifested in appropriate circumstances $C$.

However, this response is not necessary for an account of talent dispositionalism. We want to be able to say of the talented person that they have an ability to excellently develop and maintain a particular skill, even when they are not in a specific circumstance that renders doing so possible. It might be, for example, that the talented violinist is asleep, or has broken her arm, or is in a coma; in all of these situations we would still want to be able, ceteris paribus, to ascribe a talent to that violinist. This is particularly the case because a talent is an iterated disposition-it does not describe the expression or manifestation of the skill itself, but the ability to acquire, develop and maintain a skill in a particular (excellent) way. This ability must be ascribable even when the skill in question is not currently being developed. This means that a possibility condition added to new dispositionalism is unnecessary and undesirable when providing an account of talent; it would render, for instance, the talented violinist who is in a coma to be no longer deemed as talented, merely because it is not possible for her to intend to play the violin right now.

In light of this, the more desirable second response to the averted attempts objection would be to simply re-introduce the distinction between simple, specific and general abilities. Whilst it may be true that the coma prevents Betty from having the simple or specific ability to raise her arm, it still seems intuitively plausible that Betty does have a general ability to raise her arm, such that if she did try to do so in the right circumstances, then she would be able to do so. The talented violinist who is in a coma may not have a simple or specific ability to play the violin, but she does have the talent to do so, understood as general ability constituted by a disposition to excellently develop a skill for playing the violin under a set of appropriate circumstances. Because talents are general abilities rather than simple or specific ones, the averted attempts objection does not hold against a new dispositionalist account of talent.

\section{Conclusion}

In this paper I have explained and argued in support of talent dispositionalism, which has been revised as follows: $S$ has a talent for skill $A$ in circumstances $C$ iff $\mathrm{S}$ has the general disposition to excellently develop and maintain $A$ when, in circumstances $C$, 
she tries to excellently develop and maintain $A$. If this account of talent holds, it means that a talent is not an agent's potential to express a particular skill, or the skill itself, but a type of agential ability that is constituted by a general, higher-order disposition for the development and maintenance of a particular skill. This account is attractive as it meets the four desiderata that any theory of talent must be able to accommodate: (1) agent specificity, (2) domain specificity, (3) reliability, and (4) excellence. By meeting these conditions, the dispositional ability account of talent is, at the very least, extensionally adequate; to a large extent it corresponds with already held convictions that we hold with regards to what a talent is, and who should count as talented. For example, the fact that talents are constituted by dispositions and so have a modal structure, allows us to make sense of what we call 'wasted' or 'hidden' talents. These kinds of talents will be ones that are not actualised; in the case of a hidden talent it will be one that is not yet manifested, and in the case of a wasted talent, it is no longer manifested. ${ }^{19}$ In both of these cases, the ability still counts as a talent even though it is not actualised, and this is most plausibly the case by adopting a dispositional account.

Providing an account of what a talent is has allowed for the removal of conceptual confusion that is so prevalent in our everyday usage of the word, and also in the philosophical literature that touches on the normative implications of talent identification and development. The way in which we conceptualise talents, in this case as a dispositional ability, has the potential to influence and shape some of these philosophical debates. Let me briefly outline four of these areas here.

First, talent dispositionalism leaves room for an open discussion about how one acquires a talent. It is often claimed that talents are innate, native, or natural, however recent experiments undertaken by psychologists and epigeneticists point to talents arising from an iterated interaction between both genetic and environmental factors. The dispositional account does not rely on one of these positions being correct for its validity, however, what it does suggest is that when conducting research into the acquisition of talents, we ought to focus on the standard and different kinds of excellence specifically associated with skill development and maintenance, rather than the kind or standard of the skill itself.

Second, the dispositional account of talent is ethically neutral-it does not spell out what kind of skill is constitutive of a talent, or the kind of excellence that constitutes the excellence condition. It is possible, for example, to be talented at a skill that is itself immoral or used for ethically dubious ends. This leaves open the question of whether we have an ethical obligation to develop our talents, or the way in which utilizing talents may be seen as morally permissible. However, due to the fact that talents are not skills themselves but the way in which a skill is developed and maintained, research regarding the ethical dimensions of talent ought to look specifically at the nature of the way that skill is acquired and developed, and not just at the skill itself or the expression of excellence.

Third, in the literature on distributive justice, talents are discussed as problematizing social equality and fairness. Some people are more talented than others, and

\footnotetext{
19 This is not to say that all cases of talents that are no longer manifested are 'wasted', as this would imply that retired athletes who gradually lose their skills are wasting their talents. The claim is asymmetrical: wasted talents are talents no longer manifested, but some talents that are no longer manifested do not necessarily have to be 'wasted'. Thanks to an anonymous reviewer for raising this concern.
} 
it is unclear what is required of us ethically and politically in order to redistribute resources fairly. If the dispositionalist account of talent is correct, it means that a talent is an iterated disposition, and so only under appropriate and relevant circumstances and opportunities will that talent manifest in the excellent acquisition of the skill in question. Considering that talents are a particular type of dispositional potential, if we care about how they are to be fairly distributed, then we ought to look to a theory that accommodates for this. This means that a theory which focuses specifically on equality of opportunity, rather than equality of outcome, might be a natural place to start looking for answers to the questions about how to provide fair prospects for the development of talents (see for example, Fishkin 2014). This is because a theory of equality of outcome merely focuses on the product or manifestation of our abilities, potentials and opportunities, whilst a theory of equality of opportunity pays due attention to the fairness of how those potentials and abilities are themselves distributed. It may be the case that theories of justice that focus on outcome may be able to accommodate these concerns - this would be an interesting area for future research.

Finally, talent dispositionalism will have implications for how we determine the value of an agent's achievements, for those who are both talented and non-talented. There seem to be two existing positions in the debate. On the one hand, Bradford (2013; 2015, pp. 83-131) claims that what makes an achievement valuable is not the final product nor the excellence of the skill involved in its production, but the difficulty and effort involved in the achievement. In this case, whether or not an agent is talented will apparently have no bearing on the value of one's achievement. On the other hand, von Kriegstein $(2017$; 2019) and Hirji (2019) claim that an agent's talent will influence the way we ascribe value to an achievement-either increasing the likelihood of a valuable achievement, or providing a positive threshold by which to judge the value of a particular achievement.

On my account, a talent is the iterated general ability for excellent skill development and maintenance, and often this will manifest in the talented agent being able to achieve the same level of skill as a non-talented agent with comparatively less effort. As such, under Bradford's view, it seems as if the achievements of those who are not talented will be comparatively more valuable, involving more difficulty and effort to reach the same level of proficiency than someone who is talented. This means that whether or not you are talented does have a bearing on the value of your achievement, and this influence is not a positive one.

For those who consider the value of achievements to be influenced by talent ascriptions, such as von Kriegstein and Hirji, it is important to qualify that the talent merely describes the nature of the development and maintenance of the skill that gave rise to the achievement. Being talented might make it more likely to reach a high-level of skill, but it is another question altogether whether the talent, the skill, or the achievement that results from the skill, are valuable. On my account it is possible for someone to be talented at a skill that has a relatively low value ascription, and it's certainly unclear whether the talent itself is to be valued positively or negatively. This would be an interesting area for further research.

Talent dispositionalism has also made explicit a notable connection and contribution to the debate surrounding the metaphysics of ability and dispositions. The dispositional account that I have developed here highlights an explicit conceptual difference, yet 
strong connection, between ability and skill, due to the fact that a talent is not a skill tout court, but a dispositional ability for a skill. A comprehensive account of talent must develop an account of both ability and skill, and the way in which the two interact. The dispositional account that I have offered here introduces an attractive and conceptually plausible way to begin to do this.

The dispositional account of ability has recently been subject to various, seemingly devastating criticisms, but the discussion in this paper has revealed that those criticisms are not compelling when specifically considering abilities qua talent. The objections raised only hold against abilities that do not necessarily come with a reliability ascription or an excellence condition. Talents, however, are general abilities that must come with a condition of reliability and a strong success condition of excellence. This means that talents are a type of ability that can circumvent the objections raised against traditional dispositional accounts of abilities.

With this in mind, the account of talent that I have presented here has also demonstrated one wider and more general implication for the debate concerning the metaphysics of ability. By analysing a talent as one particular type of ability, certain objections raised against dispositionalism do not extend to abilities understood as talents. It might be, therefore, that the most plausible theory of the nature of ability will have to take into consideration the different types of ability that are under analysis, and tailor the account of ability to each of these distinctive types. Such a distinction has already been made with regards to general, specific and simple abilities, and talents can be considered as a further kind of general ability. It may be found, as a result of this differentiation, that it is undesirable to continue the search for a unified and overarching metaphysical account of ability, which has taken up so much of the debate.

Acknowledgements Many thanks to Michael Brady, Ben Colburn, Joaquim Giannotti and Nathan Wildman for their valuable comments on earlier drafts of this paper. I am grateful to audiences at the University of Glasgow, University of Sheffield, University of Hull, and Tilburg University, for helpful questions and discussions during conference presentations, research seminars, and work-in-progress meetings. I am also grateful to the anonymous reviewers of the final version of this paper, who raised constructive objections and comments.

Open Access This article is licensed under a Creative Commons Attribution 4.0 International License, which permits use, sharing, adaptation, distribution and reproduction in any medium or format, as long as you give appropriate credit to the original author(s) and the source, provide a link to the Creative Commons licence, and indicate if changes were made. The images or other third party material in this article are included in the article's Creative Commons licence, unless indicated otherwise in a credit line to the material. If material is not included in the article's Creative Commons licence and your intended use is not permitted by statutory regulation or exceeds the permitted use, you will need to obtain permission directly from the copyright holder. To view a copy of this licence, visit http://creativecommons.org/licenses/by/4.0/.

\section{References}

Beck, S., Olek, A., \& Walter, J. (1999). From genomics to epigenomics: A Loftier view of life. Nature Biotechnology, 17(12), 1144.

Borghini, A., \& Williams, N. E. (2008). A dispositional theory of possibility. Dialectica, 62(1), 21-41.

Bradford, G. (2013). The value of achievements. Pacific Philosophical Quarterly, 94, 204-224.

Bradford, G. (2015). Achievement. Oxford: Oxford University Press.

Carter, A. J. (2019). Exercising abilities. Synthese. https://doi.org/10.1007/s11229-019-02227-4. 
Clarke, R. (2009). Dispositions, abilities to act, and free will: The new dispositionalism. Mind, 118, 323-351.

Cohen, G. A. (2011). The currency of Egalitarian Justice, and other essays in political philosophy. Princeton: Princeton University Press.

Csikszentmihalyi, M. (1998). Fruitless polarities. Behavioral and Brain Sciences, 21(3), 411.

Dworkin, R. (2000). Sovereign virtue: The theory and practice of equality. Cambridge, MA: Harvard University Press.

Eckhardt, F., Beck, S., Gut, I. G., \& Berlin, K. (2004). Future potential of the human epigenome project. Expert Review of Molecular Diagnostics, 4(5), 609-618.

Fara, M. (2008). Masked abilities and compatibilism. Mind, 17(468), 843-865.

Fishkin, J. (2014). Bottlenecks: A new theory of equal opportunity. New York: Oxford University Press.

Greco, J. (2010). Achieving knowledge. Cambridge: Cambridge University Press.

Hirji, S. (2019). Not always worth the effort: Difficulty and the value of achievement. Pacific Philosophical Quarterly, 100, 525-548.

Honoré, A. M. (1964). Can and can't. Mind, 117(292), 463-479.

Howe, M. J. A., Davidson, J. W., Moore, D. G., \& Sloboda, J. A. (1995). Are there early childhood signs of musical ability. Psychology of Music, 23(2), 162-176.

Howe, M. J. A., Davidson, J. W., \& Sloboda, J. A. (1998). Innate talents: Reality or myth. Behavioral and Brain Sciences, 21(3), 399-442.

Hurka, T. (1993). Perfectionism. New York: Oxford University Press.

Johnston, M. (1992). How to speak of the colors. Philosophical Studies, 68, 221-263.

Kant, I. (2010). Groundwork for the metaphysics of morals, trans. \& ed. Mary Gregor. New York: Cambridge University Press.

Maier, J. (2010). Abilities. In E. N. Zalta (Ed.), The Stanford Encyclopedia of Philosophy (Spring 2018 Edition).

Maier, J. (2015). The agentive modalities. Philosophy and Phenomenological Research, 90, 113-134.

Manley, D., \& Wasserman, R. (2008). On linking dispositions and conditionals. Mind, 117, 59-84.

Martin, C. B. (1994). Dispositions and conditionals. The Philosophical Quarterly, 44(174), 1-8.

Mele, A. (2003). Agents' abilities. Noûs, 37, 447-470.

Peacocke, C. (1999). Being known. Oxford: Oxford University Press.

Rawls, J. (1999). A theory of Justice (Revised ed.). Cambridge, MA: The Belknap Press of Harvard University Press.

Ryle, G. (1949). The concept of mind. London: Hutchison.

Seel, N. M. (Ed.). (2012). Encyclopaedia of the sciences of learning. New York: Springer.

Sher, G. (2012). Talents and choices. Noûs, 46(3), 400-417.

Shields, L. (2016). Just enough: Sufficiency as a demand of Justice. Edinburgh: Edinburgh University Press.

Sloboda, J. A., Davidson, J. W., Howe, M. J. A., \& Moore, D. G. (1996). The role of practice in the development of performing musicians. British Journal of Psychology, 87(2), 287-309.

Sosa, E. (2015). Judgment and agency. Oxford: Oxford University Press.

Stanley, J., \& Williamson, T. (2017). Skill. Noûs, 51(4), 713-726.

Vetter, B. (2015). Potentiality: From dispositions to modality. Oxford: Oxford University Press.

Vetter, B. (2019). Are abilities dispositions? Synthese, 196(1), 201-220.

Vetter, B., \& Jaster, R. (2017). Dispositional accounts of ability. Philosophy Compass, 12(April), 1-11.

Vihvelin, K. (2004). Free will demystified: A dispositionalist account. Philosophical Topics, 32, 427-450. von Kriegstein, H. (2017). Effort and achievement. Utilitas, 29(1), 27-51.

von Kriegstein, H. (2019). On being difficult: Towards an account of the nature of ability. Philosophical Studies, 176, 45-64.

Weinhold, B. (2006). Epigenetics: The science of change. Environmental Health Perspectives, 114(3), A160-A 167.

Whittle, A. (2010). Dispositional abilities. Philosophers' Imprint, 10, 1-23.

Winner, E. (2000). Giftedness: Current theory and research. Current Directions in Psychological Science, $9(5), 153-156$.

Publisher's Note Springer Nature remains neutral with regard to jurisdictional claims in published maps and institutional affiliations. 